\title{
JOURNAL.RU
}

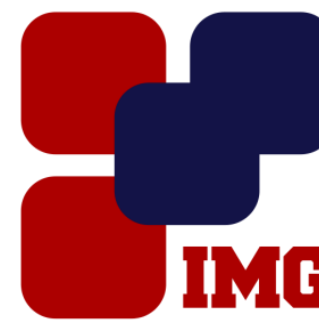

IVANOY
Management
GROUP

Диль Н.В.

АСА ДГТУ

Ростов-на-Дону, Россия

doi: 10.18411/1j-30-06-2017-52

idsp 000001:1j-30-06-2017-52

\section{Эко проектирование высотных зданий и сооружений}

При проектировании и строительстве высотных зданий и сооружений решаются множество проблем. Одной из таких является экологическое строительство. В последние годы этому вопросу стали уделять больше внимания. Это связанно с ухудшением экологических характеристик городов, с потребностью уменьшения энергопотребления и с использованием некачественных строительных материалов, которые выделяют вредные вещества.

Экологическое строительство- это возведение сооружений при котором процесс проектирования, строительства и эксплуатации минимально воздействует на окружающую среду. Можно выделить основные принципы при эко-проектировании высотных зданий:

- Снижение энергопотребления.

На снижение энергопотребления могут влиять такие факторы как правильная ориентация здания по сторонам света, использование нетрадиционных возобновляемых источников энергии (энергии солнца, воды, ветра, земли).

- Применение природных возобновляемых материалов.

Природные материалы имеют множество преимуществ перед искусственными. Например, не выделяют летучие вещества, которые опасны для здоровья человека. И к тому же обладают высокой теплопроводностью.

- Снижение уровня загрязнения окружающей среды. 
Эта проблема занимает не мало важное место в проектировании высотных зданий и сооружений. К примеру, может происходить загрязнение строительным мусором поверхностных и подземных вод. Поэтому необходимо предусмотреть специальные препятствующие мероприятия.

- Использование современного инженерного оборудования.

Современные инженерные системы создают комфортные условия для человека, который находится в высотном здании. Еще одним из преимуществ является, что они сокращают расходы на энергопотребление.

Существуют компании, которые оценивают эко-эффективность строительных объектов. Одной из таких является британская- BREEAM. Её критерии оценки считаются одними из самых строгих. Более чем 90\% сооружений, сертифицированных BREEAM, находятся в Великобритании. В России этот сертификат получили 60 объектов. Следующий стандарт, который оценивает эко-эффективность LEED. Она обосновалась в Америке. В России по этой системе выдано 12 сертификатов. Существует компания, которая адаптирована для российского строительства-GreenZoom. В её основе лежат те же принципы оценки, что в двух предыдущих. Преимуществом GreenZoom является доступность.

Из зарубежного опыта строительства экологических высотных зданий и сооружений можно отметить Hearst Tower (Башня Херст). Высота этого сооружения составляет 182 метра. Небоскрёб построен в Нью-Йорке на Манхеттене в 2006 году, архитектор Норман Фостер.
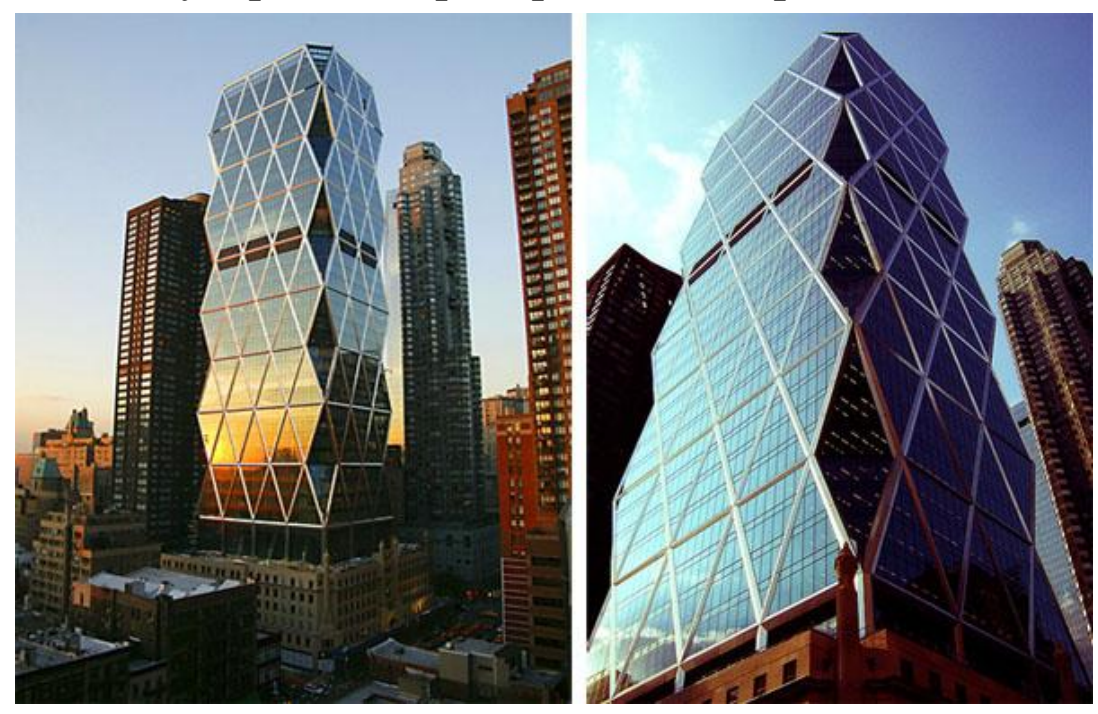

Этому сооружению присвоен золотой сертификат LEED. Это первый небоскрёб в Нью-Йорке где используется экологические нововведения. К примеру, на крыше установлена система которая собирает дождевую воду. 
Далее эта вода стекает по трубам в резервуар в подвал. Её используют для фонтанов и полива растений. Небоскрёб имеет систему энергосбережения. Основа её заключается в предельном потреблении солнечного света днём. Так же установлены электродатчики регулирующие включение и выключение освещения в помещениях. Около $90 \%$ металлических конструкций, которые использовались при строительстве Hearst Tower содержат переработанные материалы, к тому же они не токсичны и безопасны.Атриум построен из известняка. Он обладает высокой теплопроводностью, что позволяет снижать энергопотребление.

Ещё одним из примеров может послужить башня Pearl River Tower (Жемчужная река). Небоскрёб построен в 2011 году в Китае в городе Гуанчжоу. Высота сооружения 310 метров.

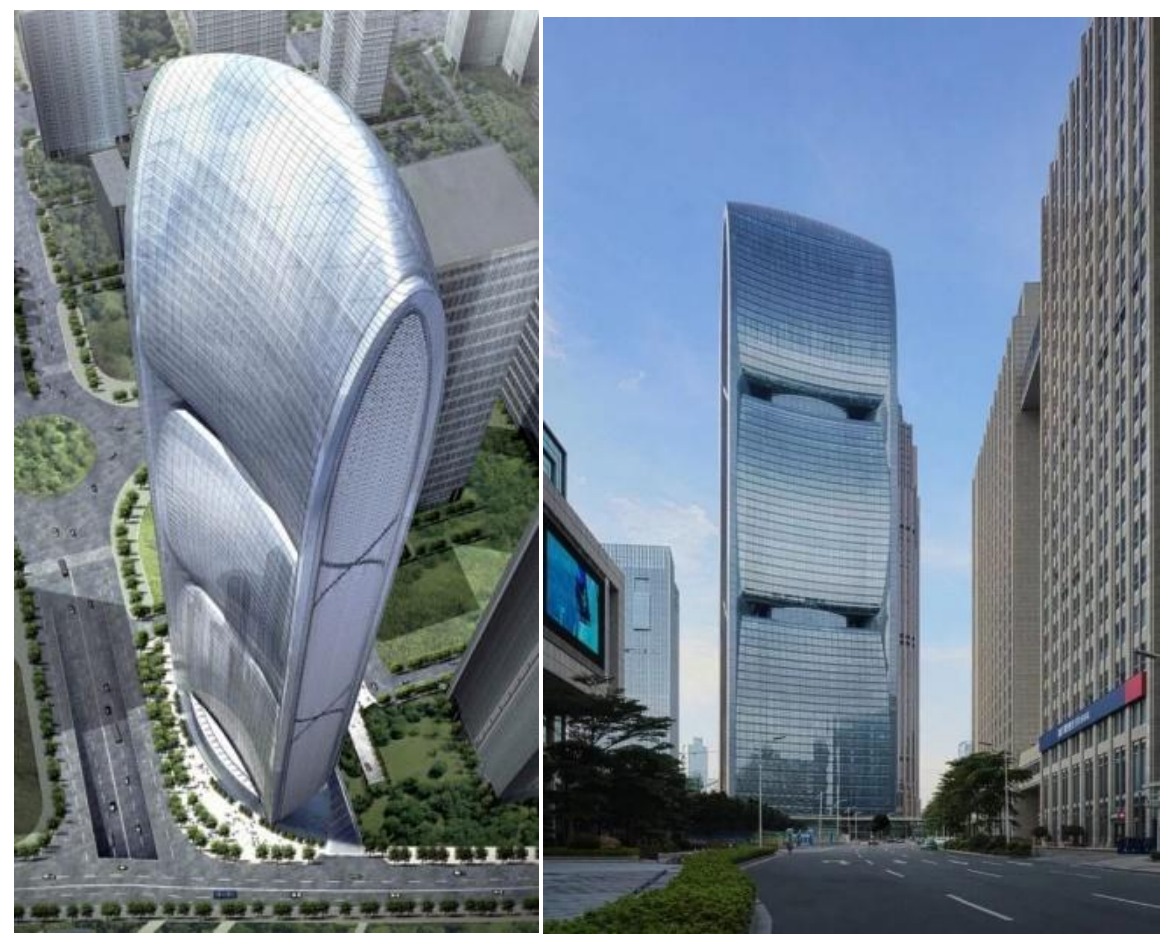

Проект выполнен архитекторами фирмы SOM. B Pearl River Tower смонтированы внутри ветровые турбины, это способствует тому, что сооружение расходует примерно на $60 \%$ меньше энергии чем ему подобные.

В здании установлены специальные окна, они скапливают солнечную энергию и оберегают сооружение от перегрева. В свою очередь жалюзи автоматически поворачиваются под углом исходя от солнечного света, это обеспечивает оптимальное освещение в течении всего дня. На крыше расположили устройства для сбора ливневой воды. Она течёт по трубам, которые расположены в полу, что создаёт условия для быстрого кондиционирования воздуха в помещениях. 
Россия только делает первые шаги к проектированию высотных экологических сооружений. Одним из примеров является «Башня Федерации». Она построена в Москве в комплексе «Москва-Сити» в 2016 году. Архитекторы проекта Сергей Чобан и Пётр Швегер. Это сооружение состоит из двух башен, которые установлены на одном основании. Высота башни «Восток» 374 метра, башни «Запад» 242 метра. Основание представляет собой шестиэтажный атриум. Остекление, которое применено при строительстве защищает от ультрафиолета и потери тепла.

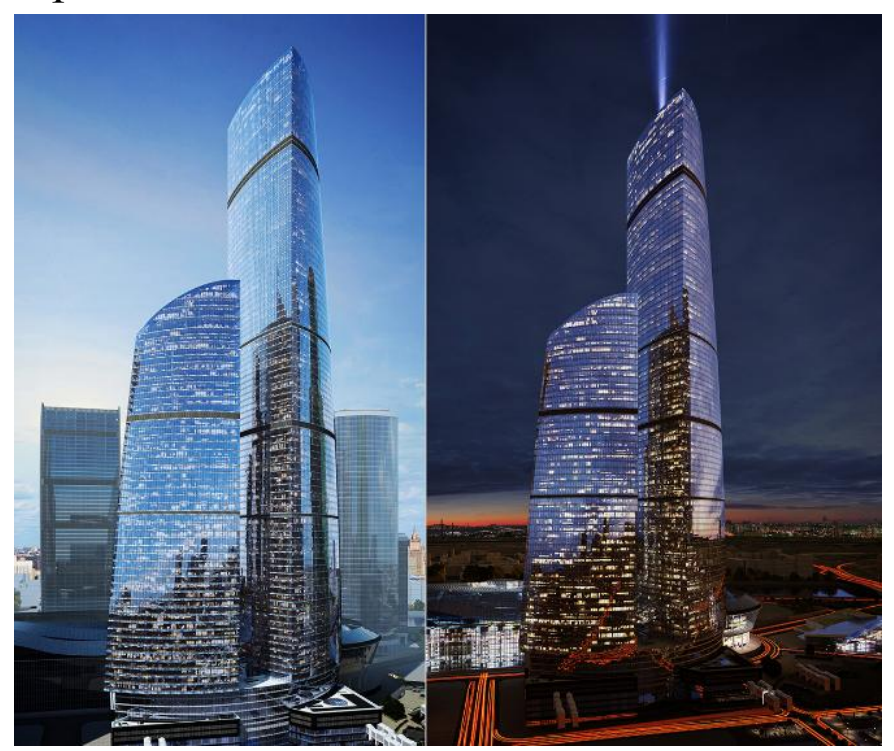

В небоскрёбе установлено современное оборудование, которое может перемещать излишки тепла и холода из одного помещения в другое. Так же здесь применяется система рекуперации тепла. Эта технология позволяет повторно использовать тепло для подогрева приточного воздуха.

В качестве нереализованного примера эко-проектирования можно взять проект «Лахта центр». Это 462 метровая башня, которая построится в СанктПетербурге в 2018 году. Архитектор Филипп Никандаров, инженер Николай Перин.

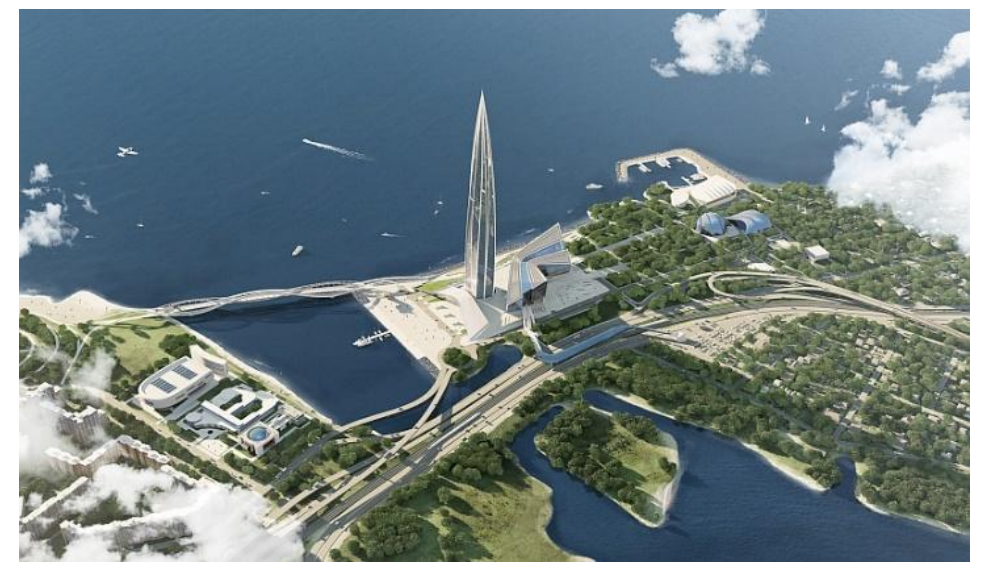


В проекте используется двойное остекление, что создаёт теплоизолирующий слой. Это позволяет повысить энергосбережение. Избыточное тепло при работе техники будет использоваться для обогрева помещений. Так же в башне будут установлены датчики присутствия для экономии воды и электроэнергии. Будут размещены специальные жалюзи, которые меняют угол поворота в зависимости от солнечного света, что даёт автоматически регулировать уровень освещенности в помещениях.

Предусмотрено применение очищенной ливневой воды для полива. Озеленённые стены и кровля будут обеспечивать дополнительное поступление кислорода. При строительстве «Лахта центр» применены экологичные материалы и материалы вторичной переработки.

Интерес к проектированию экологических высотных зданий и сооружений вызван в целях экономического сбережения, улучшения условий окружающей среды и жизни человека. Поэтому необходимо внедрять все принципы «зелёного строительства».

\section{$* * *$}

1. Особенности проектирования высотных зданий. Генералов В.П. 2009

2. Основы экологической архитектуры. Казанцев П.А. 2009

3. Проектирование современных высотных зданий. СюйПэйфу, Фу Сюеи, Ван Цуйкунь, СяоЦунчжэнь. 2008

4. Экологическое проектирование и экспертиза. Питулько В.М., Иванова В.В.

5. http://lakhta.center/ru/about/arch/

6. http://www.expo-mos.ru/projects/buildgreen.htm

7. https://www.rmnt.ru/story/realty/367711.htm 